\title{
Extramedullary acute myeloid leukemia: leukemic pleural effusion, case report and review of the literature
}

\author{
Naveen Pemmaraju ${ }^{1}$, Elaine Chang ${ }^{1}$, Naval Daver ${ }^{1}$, Keyur Patel $^{2}$, Jeffrey Jorgensen ${ }^{2}$, Bradley Sabloff ${ }^{3}$, \\ Srdan Verstovsek ${ }^{1}$ and Gautam Borthakur ${ }^{1}$
}

' Department of Leukemia, The University of Texas MD Anderson Cancer Center, Houston, TX, USA

2 Department of Pathology, The University of Texas MD Anderson Cancer Center, Houston, TX, USA

${ }^{3}$ Department of Radiology, The University of Texas MD Anderson Cancer Center, Houston, TX, USA

\section{Edited by:}

Sattva S Neelapu, The University of Texas MD Anderson Cancer Center, USA

\section{Reviewed by:}

Jeffrey H Lipton, University Health Network, Canada

Yago Nieto, The University of Texas MD Anderson Cancer Center, USA

Myriam Foglietta, University of Turin, Italy

\section{*Correspondence}

Naveen Pemmaraju, Department of Leukemia, The University of Texas MD Anderson Cancer Center, 1515

Holcombe Blvd., Unit 0428, Houston, TX 77030, USA

e-mail:npemmaraju@

mdanderson.org
Objective and Importance: Malignant pleural effusions occur in the setting of both solid and hematologic malignancies. Pleural effusion caused by leukemic infiltration is an unusual extramedullary manifestation of acute myeloid leukemia (AML) with fewer than 20 cases reported (1-11). We report a case of pericardial and pleural effusions in a patient with AML and review the literature.

Clinical Presentation: In this case, a 55-year-old man with previous history of myeloproliferative neoplasm experienced transformation $A M L$, heralded by appearance of leukemic pleural effusions. The patient was identified to have leukemic pleural effusion based on the extended cytogenetic analysis of the pleural fluid, as morphologic analysis alone was insufficient.

Intervention:The patient was treated with hypomethylator-based and intensive chemotherapy strategies, both of which maintained resolution of the effusions in the remission setting.

Conclusion: Due to the rarity of diagnosis of leukemic pleural effusions, both cytogenetic and fluorescence in situ hybridization testing are recommended. Furthermore, systemic chemotherapy directed at the AML can lead to complete resolution of leukemic pleural effusions.

Keywords: extramedullary AML, acute myeloid leukemia, malignant pleural effusion

\section{OBJECTIVE AND IMPORTANCE}

Pleural effusion caused by leukemic infiltration is an unusual extramedullary manifestation of acute myeloid leukemia (AML), but may be more common than previously thought. Fewer than 20 cases have been reported (1-11). We report a case of pericardial and pleural effusions in a patient with AML and review the literature.

\section{CASE REPORT: CLINICAL PRESENTATION}

A 55-year-old man with polycythemia vera (PV) had pancytopenia, moderate pericardial effusion, and bilateral pleural effusions. He had an 8-year history of PV treated with hydroxyurea and anagrelide. He was in his usual state of health until 6 weeks prior to presentation to our institution when he went to an outside hospital for a cholecystectomy.

In the weeks following his surgery, he developed nausea and vomiting, and was found to have a duodenal ulcer and esophageal erosions. During treatment for these complications, he was noted to have a moderate-sized pericardial effusion and pancytopenia. A bone marrow biopsy showed progression of PV to AML.

He was referred to our institution with shortness of breath, chest pain, and pancytopenia. Bone marrow biopsy at our institution confirmed the diagnosis of AML with complex cytogenetics including trisomy 8 , trisomy 9 , trisomy 21 , and molecular analysis positive for $J A K 2 \mathrm{~V} 617 \mathrm{~F}$ mutation.

The patient had pericardial and exudative pleural effusions (Figure 1) causing increased oxygen requirement. He underwent thoracentesis and pericardiocentesis. Work-up for infectious, rheumatologic, and cardiac causes of the effusions was negative. Cytology of both effusions revealed reactive mesothelial cells in a background of acute inflammation, but no malignant cells were identified. Flow cytometry was done, and the cells in both the pleural and pericardial fluid were predominantly (70\%) of a phenotype consistent with basophils. Repeat thoracentesis with cytogenetic analysis was performed. Fluorescent in situ hybridization was significant for trisomy 8 , trisomy 9 , and trisomy 21 in the pleural effusion. These cytogenetic abnormalities were identical to the those detected on the presenting bone marrow, and were found in the majority of the cells analyzed, thereby confirming the presence of leukemic pleural effusions.

\section{INTERVENTION}

The patient was initially treated with decitabine for 5 days. He had dramatic improvement in performance status during the hospital stay and then also went on to receive twice-daily fludarabine and cytarabine (BIDFA) for an additional 4-day first cycle. $\mathrm{He}$ responded with an approximately $50 \%$ reduction of blasts 


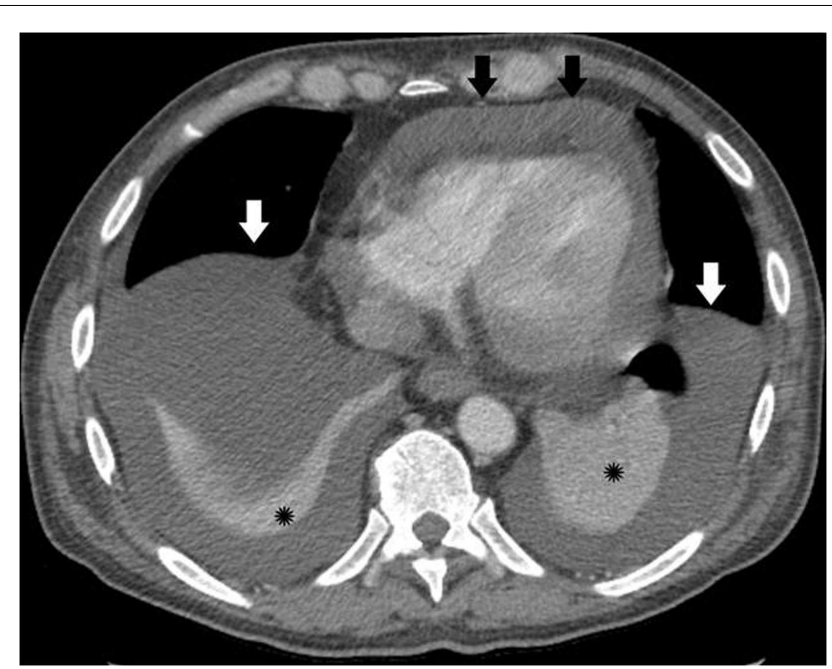

FIGURE 1 | Pre-treatment computed tomography (CT) image with intravenous (IV) contrast, demonstrating bilateral pleural effusions (white arrows) and moderate-sized pericardial effusion (black arrows), prior to thoracentesis, pericardiocentesis, or chemotherapy. Black asterisk $=$ atelectatic lung.

and was given a second cycle of therapy with BIDFA for 4 days. Complete remission was achieved after the second cycle, but he developed neutropenic fevers, sepsis, and bacterial endocarditis, with decreased performance status to 2 . In the setting of continued complete remission but with decreased performance status and co-morbidities, he was switched to single agent decitabine, which he tolerated well for four cycles. His performance status improved back to 1 , and imaging continued to demonstrate near total resolution of effusions in the absence of requiring any further thoracenteses (Figure 2). He was being considered for stem cell transplantation. Unfortunately, the AML ultimately relapsed prior to stem cell transplant, and the patient died 11 months after his transformation to AML in the setting of multi-organ failure and diffused alveolar hemorrhage, although without effusions.

\section{DISCUSSION}

Clinically significant pleural effusions, regardless of etiology, are rarely encountered in patients with AML. A retrospective review of all patients with acute leukemia, myelodysplastic syndrome (MDS), or myeloproliferative neoplasm (MPN) who underwent pleural procedures at our institution from 1997 to 2007 found that $2 \%$ (111 patients out of 6,442) required thoracentesis, chest tube insertion, or pleural catheter placement. Sixty-nine of the patients had AML; among these, 39 pleural effusions were infectious and 25 were leukemic, determined by positive cytology or flow cytometry (12). However, the incidence of leukemic pleural effusions may be increasing as a result of longer survival with improved chemotherapies (8). In their 10 year review, Faiz et al. noted that the role of infection was similar to that reported in previous autopsy series, albeit malignant infiltrative effusions were more frequent than in earlier series (12). Our review of the literature yielded 13 individual case reports, summarized in Table $\mathbf{1}$.

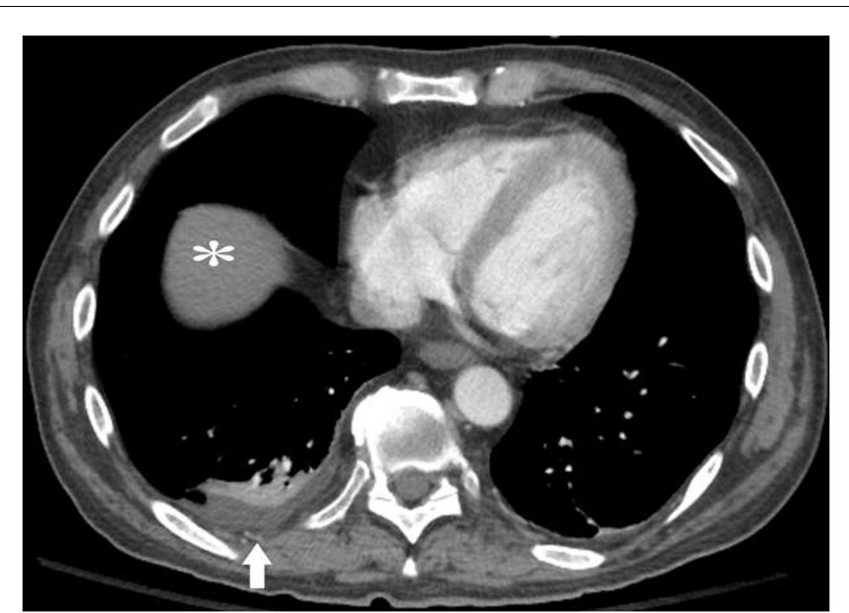

FIGURE 2 | Post-treatment CT image after two cycles of fludarabine and cytarabine and four cycles of decitabine alone. White arrow $=$ residual small right pleural effusion. No left pleural effusion or pericardial effusion. White asterisk = liver.

AML is not a common cause of pleural effusions. A 14-year study of 5,888 pleural fluid specimens by Johnston et al. found that $10 \%$ of the effusions were malignant, of which $15 \%$ were attributable to "leukemia" or "lymphoma," but more specific histopathologic diagnosis were not available (13). A 2-year retrospective analysis of pleural fluid cytological specimens in India found that of 898 samples, 164 (18\%) were malignant, the majority of hematologic malignancies were Non-Hodgkin's lymphoma, and none were AML (14). Similarly, a more recent review of 4,684 consecutive pleural fluid specimens received in Turkey found only 1 positive for AML (15).

Other sites of extramedullary leukemia (EML) have been associated with FAB M4-M5 subtypes, CD56 (+) blasts, cytogenetic abnormalities including $\mathrm{t}(8: 21)$, inversion 16 , infant leukemia, 11q abnormalities, cellular immune dysfunction, and allogeneic stem cell transplantation. More studies are needed to demonstrate statistically significant relationships with these variables in patients with AML pleural effusions. In their review of AML, ALL, and MDS/MPN collectively, Faiz et al. found that the presence of pleural effusions did not influence survival but did portend more aggressive disease if the hematologic malignancy was diagnosed within 6 months (12).

All the cases described herein occurred concomitantly with or followed the onset of systemic disease, although in some circumstances EML may be discovered prior to the medullary diagnosis. Still, the timing of the development of a pleural effusion varied among these cases, from initial presenting symptom to a component of progression in patients with refractory disease or as a harbinger of relapse in patients with marrow remission. Additionally, as noted before, leukemic pleural effusions can occur as an isolated finding or in association with parenchymal lung disease (16).

This case illustrates the importance of cytogenetic analysis on pleural fluid with fluorescence in situ hybridization (FISH) or comparative genomic hybridization $(\mathrm{CGH})$ in patients with AML 
Table 1 | Summary of case reports of AML pleural effusion

\begin{tabular}{|c|c|c|c|c|c|}
\hline Author (Ref.) & Sex & Age (year) & $\begin{array}{l}\text { Leukemia status at leukemic } \\
\text { effusion diagnosis }\end{array}$ & $\begin{array}{l}\text { Treatment after diagnosis } \\
\text { of leukemic effusion }\end{array}$ & Overall outcome \\
\hline Raynolds (1) & M & 26 & AML & Supportive care & Death 5 months after diagnosis \\
\hline Ohe et al. (2) & $\mathrm{M}$ & 51 & $\mathrm{CD} 7+\mathrm{AML}$ & $\begin{array}{l}\text { Induction araC + daunorubicin, } \\
\text { then autologous HSCT }\end{array}$ & $\begin{array}{l}\text { Complete remission for at least } \\
8 \text { months }\end{array}$ \\
\hline Park et al. (3) & M & 41 & $\begin{array}{l}\text { AML recurrence ( } 31 \text { months } \\
\text { after) } \mathrm{HSCT} \text {, in } B M \text { remission }\end{array}$ & Not reported & Not reported \\
\hline Khan et al. (4) & $\mathrm{F}$ & 71 & $\begin{array}{l}\text { AML M5 (acute monocytic } \\
\text { leukemia) }\end{array}$ & Induction araC + daunorubicin & $\begin{array}{l}\text { Death } 22 \text { days after initiation of } \\
\text { induction chemotherapy }\end{array}$ \\
\hline Farray et al. (5) & $\mathrm{F}$ & 45 & $\begin{array}{l}\text { Acute megakaryoblastic } \\
\text { leukemia (M7) }\end{array}$ & Not reported & Not reported \\
\hline Fatih (6) & M & 50 & AML M1 & $\begin{array}{l}3+7 \text { induction } \\
\text { idarubicin }+ \text { cytarabine }\end{array}$ & $\begin{array}{l}\text { Effusion resolved, but leukemia was } \\
\text { refractory; death } 3 \text { months after } \\
\text { discharge from clinic }\end{array}$ \\
\hline Huang (7) & $\mathrm{F}$ & 56 & $\begin{array}{l}\text { CMMoL with transformation } \\
\text { to } \mathrm{AML}\end{array}$ & $\begin{array}{l}3+7 \text { induction } \\
\text { idarubicin }+ \text { cytarabine }\end{array}$ & $\begin{array}{l}\text { Respiratory failure; death on } \\
\text { hospital day } 64\end{array}$ \\
\hline Stoll (8) & M & 54 & AML-MDS & $\begin{array}{l}\text { None, ineligible due to renal } \\
\text { function }\end{array}$ & $\begin{array}{l}\text { Home hospice; death } 1 \text { week after } \\
\text { discharge }\end{array}$ \\
\hline Ou et al. (9) & $\mathrm{M}$ & 53 & $\begin{array}{l}\text { AML with recurrent genetic } \\
\text { abnormalities }\end{array}$ & $\begin{array}{l}3+7 \text { induction } \\
\text { idarubicin }+ \text { cytarabine }\end{array}$ & $\begin{array}{l}\text { Complete remission with first } \\
\text { induction, but effusions did not } \\
\text { resolve. After re-induction with } \\
\text { high-dose cytarabine, effusions } \\
\text { resolved. Later underwent HSCT, } \\
\text { remained disease-free }\end{array}$ \\
\hline Chang (10) & $\mathrm{F}$ & 74 & AML & Induction cytarabine & $\begin{array}{l}\text { Effusions resolved; complete } \\
\text { remission for at least } 11 \text { months }\end{array}$ \\
\hline Chang (10) & $\mathrm{M}$ & 75 & $\begin{array}{l}\text { CMMoL with transformation } \\
\text { to } \mathrm{AML}\end{array}$ & $\begin{array}{l}\text { None, ineligible due to poor } \\
\text { performance status }\end{array}$ & $\begin{array}{l}\text { Death } 1 \text { month after diagnosis of } \\
\text { pleural myeloid sarcoma }\end{array}$ \\
\hline Chang (10) & $M$ & 74 & Refractory AML & Supportive care & $\begin{array}{l}\text { Death } 1 \text { month after confirmed } \\
\text { leukemic pleural effusion }\end{array}$ \\
\hline Agrawal (11) & $M$ & 45 & AML M2 & Induction cytarabine & Death 1 week later \\
\hline
\end{tabular}

HSCT, hematopoietic stem cell transplant; BM, bone marrow; araC, cytarabine; CMMoL, chronic myelomonocytic leukemia.

presenting with pleural effusion (17) to prevent misdiagnosis as drug toxicity, infection, secondary malignancy, or autoimmune phenomenon related effusions. Immunohistochemistry is also helpful (17-20). In addition to their role in diagnosis, cytogenetic characteristics may change treatment options and prognosis for subgroups of AML patients.

A recent review suggested that EML is more common than previously thought, and that routine baseline pre-treatment imaging studies with PET/CT may be warranted to help establish the true incidence of EML (21). Additionally, any patient with AML presenting with a pleural effusion should routinely undergo cytogenetic evaluation as a part of the pleural fluid analysis.

Further studies are warranted to elucidate the prognostic significance of AML pleural effusions and on the safety and efficacy of newer targeted therapies. Success has been reported with standard induction chemotherapy, stem cell transplant, and as with our case presentation, with hypomethylating agent decitabine as therapeutic options for patients with such unique presentations.

\section{CONCLUSION}

Leukemic effusions are rare but the incidence may be underestimated. Patients with AML presenting with a pleural effusion should receive cytogenetic studies as a routine part of the pleural fluid analysis. Systemic chemotherapy has yielded successful results with resolution of effusions and complete remission. Further prospective studies are warranted to better characterize the incidence and outcomes of leukemic pleural and pericardial effusions from AML. 


\section{REFERENCES}

1. Raynolds AH, Olivetti RG, Ekstrand RW. Aleukemic stem cell leukemia with polyserositis: report of case. Blood (1955) 10:81-6.

2. Ohe K, Okamura T, Arima F, Kamura T, Takamatsu Y, Murakawa M, et al. CD7 positive acute myelogenous leukemia exhibiting pleural involvement as an initial manifestation. Rinsho Ketsueki (1994) 35(6):552-6.

3. Park J, Park SY, Cho HI, Lee D. Isolated extramedullary relapse in the pleural fluid of a patient with acute myeloid leukemia following allogeneic BMT. Bone Marrow Transplant (2002) 30:57-9. doi:10.1038/sj.bmt.1703572

4. Khan MY, Hussein KK, Walter MG, Hasan MK, Kern W, Kharfan-Dabaja MA. Granulocytic sarcoma presenting with malignant anasarca in a patient with secondary acute myeloid leukemia. Int J Hematol (2004) 79(3):250-2. doi:10.1532/IJH97.NA0305

5. Fatih T, Selim Y, Mesut A, Demirel YN, Yuksel P. An unusual cause of unilateral pleural effusion in the setting of aortic stenosis: acute myeloid leukemia. Intern Med (2007) 46(6):325-7. doi:10.2169/internalmedicine.46.6004

6. Farray D, Ali-Masri H, Hattersley E, Smith SE. Megakaryoblastic leukemia with involvement of the pleural fluid. Am J Hematol (2005) 79(3):238-9. doi:10.1002/ajh.20357

7. Huang CT, Kuo PH, Yao M, Tsai YJ, Yang PC. Pleural effusion heralds acute leukemic transformation of chronic myelomonocytic leukemia. South Med J (2008) 101(12):1279-80. doi:10.1097/SMJ.0b013e318189aa39

8. Stoll LM, Duffield AS, Johnson MW, Ali SZ. Acute myeloid leukemia with myelodysplasia-related changes with erythroid differentiation involving pleural fluid: a case report and brief cytopathologic review. Diagn Cytopathol (2011) 39(6):451-4. doi:10.1002/dc. 21470

9. Ou MC, Hwang WL, Teng CL. Leukaemic pleural effusion in acute myeloid leukaemia. Br J Haematol (2011) 154:669. doi:10.1111/j.1365-2141. 2011.08722.x

10. Chang H. Acute myeloid leukemia with leukemic pleural effusion. Diagn Cytopathol (2013) 41(10):909-13. doi:10.1002/dc.22859

11. Agrawal R. Acute myeloid leukaemia (AML) presenting as a bilateral pleural effusion. J Clin Diagn Res (2013) 7(1):187. doi:10.7860/JCDR/2012/4633.2705

12. Faiz SA, Bashoura L, Lei X, Sampat KR, Brown TC, Eapen GA, et al. Pleural effusions in patients with acute leukemia and myelodysplastic syndrome. Leuk Lymphoma (2013) 54(2):329-35. doi:10.3109/10428194.2012. 713478

13. Johnston W. The malignant pleural effusion. A review of cytopathologic diagnoses of 584 specimens from 472 consecutive patients. Cancer (1985) 56:905-9. doi:10.1002/1097-0142(19850815)56:4<905::AIDCNCR2820560435>3.0.CO;2-U
14. Awasthi A, Gupta N, Srinivasan R, Nijhawan R, Rajwanshi A. Cytopathological spectrum of unusual malignant pleural effusions at a tertiary care centre in North India. Cytopathology (2007) 18:28-32. doi:10.1111/j.1365-2303.2007.00382.x

15. Cakir E, Demirag F, Aydin M, Erdogan Y. A review of uncommon cytopathologic diagnoses of pleural effusions from a chest diseases center in Turkey. Cytojournal (2011) 8:13. doi:10.4103/1742-6413.83026

16. Alexandrakis MG, Passam FH, Kyriakou DS, Bouros D. Pleural effusions in hematologic malignancies. Chest (2004) 125:1546-55. doi:10.1378/chest.125.4. 1546

17. Pileri SA, Ascani S, Cox MC, Campidelli C, Bacci F, Piccioli M, et al. Myeloid sarcoma: clinico-pathologic, phenotypic and cytogenetic analysis of 92 adult patients. Leukemia (2007) 21:340-50. doi:10.1038/sj.leu.2404491

18. Byrd JC, Edenfield WJ, Shields DJ, Dawson NA. Extramedullary myeloid cell tumors in acute non-lymphocytic leukemia: a clinical review. J Clin Oncol (1995) 13:1800-16.

19. Bakst RL, Tallman MS, Douer D, Yahalom J. How I treat extramedullary acute myeloid leukemia. Blood (2011) 118(14):3785-93. doi:10.1182/blood-2011-04347229

20. Avni B, Koren-Michowitz M. Myeloid sarcoma: current approach and therapeutic options. Ther Adv Hematol (2011) 2:309-16. doi:10.1177/2040620711410774

21. Ohanian M, Faderl S, Ravandi F, Pemmaraju N, Garcia-Manero G, Cortes J, et al. Is acute myeloid leukemia a liquid tumor? Int J Cancer (2013) 133(3):534-43. doi:10.1002/ijc.28012

Conflict of Interest Statement: The authors declare that the research was conducted in the absence of any commercial or financial relationships that could be construed as a potential conflict of interest.

Received: 26 March 2014; accepted: 16 May 2014; published online: 02 June 2014. Citation: Pemmaraju N, Chang E, Daver N, Patel K, Jorgensen J, Sabloff B, Verstovsek $S$ and Borthakur G (2014) Extramedullary acute myeloid leukemia: leukemic pleural effusion, case report and review of the literature. Front. Oncol. 4:130. doi: 10.3389/fonc.2014.00130

This article was submitted to Hematology Oncology, a section of the journal Frontiers in Oncology.

Copyright (C) 2014 Pemmaraju, Chang, Daver, Patel, Jorgensen, Sabloff, Verstovsek and Borthakur. This is an open-access article distributed under the terms of the Creative Commons Attribution License (CC BY). The use, distribution or reproduction in other forums is permitted, provided the original author(s) or licensor are credited and that the original publication in this journal is cited, in accordance with accepted academic practice. No use, distribution or reproduction is permitted which does not comply with these terms. 